\title{
Simultaneous Extraction and Detection of Ochratoxin A and Citrinin in Rice
}

\author{
Helen C. S. Hackbart, * Luciana Prietto, Ednei G. Primel, Jaqueline Garda-Buffon and \\ Eliana Badiale-Furlong
}

\author{
Escola de Química e Alimentos, Fundação Universidade Federal do Rio Grande, \\ CP 474, 96201-900 Rio Grande-RS, Brazil
}

\begin{abstract}
Este estudo comparou quatro procedimentos de extração para a determinação simultânea das micotoxinas citrinina e ocratoxina A em amostras de arroz. Os procedimentos de Soares e Rodriguez-Amaya, Tanaka e os métodos de extração QuEChERS (Quick, Easy, Cheap, Effective, Rugged and Safe) e por ultrassom foram comparados em termos de geração de resíduos, limite de detecção, limite de quantificação e recuperação simultânea de micotoxinas. O procedimento de Soares e Rodriguez-Amaya e a extração por ultrassom apresentaram as menores recuperações, 83 e $55 \%$ para a ocratoxina A (OTA) e 55 e $48 \%$ para citrinina (CIT), respectivamente. O procedimento de Tanaka e a extração QuEChERS tiveram recuperações de 98 e 105\% para OTA e 64 e $78 \%$ para CIT, respectivamente. Este último permitiu a extração simultânea das duas micotoxinas com uma redução de até 25 vezes na quantidade de solventes.
\end{abstract}

This study compared four extraction procedures for the simultaneous determination of mycotoxins ochratoxin A and citrinin in samples of rice. Soares and Rodriguez-Amaya and Tanaka procedures and the extraction methods QuEChERS (Quick, Easy, Cheap, Effective, Rugged and Safe) and by ultrasound were compared in terms of residue generation, limit of detection, limit of quantification and simultaneous recovery of mycotoxins. Soares and Rodriguez-Amaya and the method by ultrasound presented the lowest recoveries, 83 and 55\% for ochratoxin A (OTA) and 48 and 55\% for citrinin (CIT), respectively. Tanaka procedure and QuEChERS method presented the highest recoveries, 98 and $105 \%$ for OTA and 64 and $78 \%$ for CIT, respectively. The latter enabled the simultaneous extraction of the two mycotoxins, with a reduction of up to 25 times of the amount of the involved solvent.

Keywords: rice, occurrence, ochratoxin A, citrinin, extraction method

\section{Introduction}

Fungi produce a large variety of toxic secondary metabolites called mycotoxins. ${ }^{1}$ These compounds comprise several chemical structures including some relatively simple ones, ${ }^{1}$ which occur in mycelium of filamentous fungi, normally after a period of balanced growth followed by stress conditions. ${ }^{2,3}$ Aspergillus, Penicillium and Fusarium are among the fungal genera that occur in food and that have toxigenic species, such as Aspergillus ochraceus and Penicillium citrinum, the main producers of ochratoxin A and citrinin, respectively.,

Ochratoxin A (OTA) (N-\{[(3R)-5-chloro-8-hydroxy-3methyl-1-oxo-3,4-dihydro- $1 H$-isochromen-7-yl]carbonyl $\}$ L-phenylalanine, Figure 1) is classified by the International

*e-mail: hhackbart@hotmail.com<smiles>CC1Cc2c(Cl)cc(C(=O)NC(Cc3ccccc3)C(=O)O)c(O)c2C(=O)O1</smiles>

Figure 1. Chemical structure of ochratoxin A.

Agency for Research on Cancer (IARC from World Health Organization (WHO)) as a probably carcinogenic agent for humans (Group 2B, IARC). ${ }^{6}$ It has been also correlated to the Balkan endemic nephropathy (BEN). ${ }^{7}$ Its presence was detected in many stored and dry foods, ${ }^{8,9}$ such as corn, wheat, oats, beans, nuts, peanuts, rice, barley, sorghum, cotton seed, coffee beans, cocoa and spices. ${ }^{10-13}$

Citrinin (CIT) [ $[(3 R, 4 S)$-8-hydroxy-3,4,5-trimethyl6-oxo-4,6-dihydro-3H-isochromene-7-carboxylic acid, 
Figure 2] has been known since 1931, when it was isolated from Penicilliun citrinum and, afterwards, from the Australian plant Crotolaria crispata. ${ }^{14,15}$ This mycotoxin is associated with cases of porcine nephropathy and has been found as a contaminant in corn, rice, wheat and other grains, ${ }^{16,17}$ chees $^{18}$ and fruits during senescence. ${ }^{19}$ The adverse effects caused by CIT on the human body are chronic rather than acute. It has been demonstrated that its intake may cause hepatic and renal failure in the long run. ${ }^{4}$<smiles>CC1=C2C(=COC(C)C2C)C(=O)C(C(=O)O)=C1O</smiles>

Figure 2. Chemical structure of citrinin.

The development of methodologies that allows the simultaneous extraction of these mycotoxins ${ }^{20}$ in different matrices has been encouraged since the toxicity was determined. ${ }^{21}$ Extractions in the liquid phase were largely studied for the determination of ochratoxin $\mathrm{A},{ }^{22}$ and most of the validated methods were based on the extraction of ochratoxin A and citrinin through the solubility of these compounds in organic solvents ${ }^{23}$ or alkaline solutions. ${ }^{24}$ These methods were satisfactory for the extraction from liquid matrices, but not from solid samples..$^{25}$ The organic solvent mixtures that were used for solid matrices have shown low recoveries and high amount of solvent residues. ${ }^{26}$

The most difficult task for the determination of mycotoxins in solid matrices happens in the extraction phase because they can produce emulsions and foams with the matrices during this process. ${ }^{27,28}$ One of the phases of the extraction process must remove the lipids and proteins before the chromatographic analysis. The extraction with acetonitrile has been traditionally used ${ }^{27}$ because it enables the precipitation of proteins and the addition of hexane removes the soluble interference. ${ }^{28}$

The development of new extraction techniques that could decrease the time of extraction, the consumption of solvents, the exposure of the analyst, the generation of residue and the costs would be ideal for the extraction of these contaminants from food and would make it easier to guarantee food safety. Methods such as Soares and Rodriguez-Amaya ${ }^{27}$ and Tanaka ${ }^{28}$ are commonly used for the determination of mycotoxins in different matrices with adequate analytical efficiency. However, their disadvantage is the large amount of needed solvents for the extraction. This fact makes difficult to establish an analytical routines which can be accessible to most laboratories that are involved in the extraction of mycotoxins since both the discharge of residues and the cost of solvents are challenges to be faced.

The QuEChERS (Quick, Easy, Cheap, Effective, Rugged and Safe $)^{29}$ method is a procedure that has been adopted for the extraction of pesticides ${ }^{30-32}$ due to its quickness and accessible cost. Another interesting feature is that it is efficient for the extraction of analytes with different polarities in trace level in complex samples with some reliability. ${ }^{33-35}$ The extraction of mycotoxin that uses solvents under the operation of ultrasound is also being considered interesting, once it provides the extraction of compounds with distinct polarities, imputed the optimization of the solute-solvent contact. ${ }^{36}$

This study aims at comparing the phase of extraction and purification of four methods regarding its ability to simultaneously extract ochratoxin A and citrinin in rice, by using high performance liquid chromatography with a photodiode array detector (HPLC-PDA). Soares and Rodriguez-Amaya ${ }^{27}$ and Tanaka ${ }^{28}$ procedures and the extractions which use modified QuEChERS (applied with some modifications, Anastassiades et al. $)^{29}$ and ultrasound (Liazid et al. ${ }^{36}$ ) were compared in terms of residue generation, limit of detection (LOD), limit of quantification (LOQ) and simultaneous recovery of mycotoxins.

\section{Experimental}

\section{Samples}

Rice bran was used to evaluate the extraction and purification phases of the different methods. The applicability was evaluated by a study of the simultaneous occurrence of the mycotoxins in rice (Oryza sativa, L.) samples. The samples were from experimental fields at Instituto Riograndense do Arroz (IRGA) in Cachoeirinha City (Rio Grande do Sul State, Brazil). After the harvest, the grains were milled and 36 samples were sorted out: $(n=6)$ rough rice, $(n=6)$ parboiled rough rice, $(n=6)$ polished rice, $(n=6)$ white polished rice, $(n=6)$ bran and $(n=6)$ parboiled bran. Samples $(n=2)$ of rough rice and bran which had been stored in silos for 18 months were also collected. The 38 samples were grounded in a knife grinder and sieved separating the $0.5 \mathrm{~mm}$ fractions.

\section{Reagents and solvents}

Ochratoxin A and citrinin were purchased from SigmaAldrich (São Paulo, Brazil) purity $>98 \%$. The reagents methanol and acetonitrile of chromatographic grade were purchased from Mallinckrodt (Phillipsburg, NJ, USA). 
Phosphoric acid (85\%) of analytical grade, glacial acetic acid, hexane and benzene were purchased from Merck (Darmstadt, Germany). Chloroform and potassium chloride, sodium chloride, ammonium sulfate and magnesium sulfate were purchased from Synth (São Paulo, Brazil). Sodium acetate was purchased from Vetec (Rio de Janeiro, Brazil) and diatomaceous earth from Nuclear (Celite 545, São Paulo, Brazil). Ultrapure water was produced by Direct-Q $\mathrm{UV}^{\circledR}{ }^{\circledR}$ system (Millipore, Bedford, MA, USA).

\section{Preparation of standard solution of ochratoxin A and citrinin}

Analytical and storage standard solutions were individually prepared from commercial containers containing $5 \mathrm{mg}$ of mycotoxins and each mycotoxin was dissolved in $100 \mathrm{~mL}$ of benzene:acetonitrile $(98: 2, \mathrm{v} / \mathrm{v})$. The storage solutions were diluted in order to produce standard solutions, whose concentrations were determined by the mass in the container and the final volume of the solution. The concentrations were spectrophotometrically confirmed in a Cary 100 equipment from Varian (USA). The concentration of the values of molar absorptivity $(\varepsilon) 5440$ and $5490 \mathrm{~mol} \mathrm{~cm}^{-1}$ and the wavelength of maximum absorbance 333 and $321 \mathrm{~nm}$ for OTA and CIT, respectively, were considered for the estimative. ${ }^{6}$ The solutions were stored in an amber container and chilled at $4{ }^{\circ} \mathrm{C}$, until use.

\section{Extraction and purification}

The phases of the extraction and purification, which were described in validated methods by four authors, were compared.

The method of extraction and purification described by Soares and Rodriguez-Amaya ${ }^{27}$ (procedure 1) used $50.00 \mathrm{~g}$ of sample, homogenized in a blender for $5 \mathrm{~min}$ with $300 \mathrm{~mL}$ of methanol:potassium chloride at 4\%, (9:1 v/v). After filtration, $150 \mathrm{~mL}$ was collected and mixed with $150 \mathrm{~mL}$ of ammonium sulfate at $30 \%$ (clarifying) with $50 \mathrm{~mL}$ of diatomaceous earth. The mixture rested for $5 \mathrm{~min}$ and was filtrated. Then, $150 \mathrm{~mL}$ of distilled water was added to $150 \mathrm{~mL}$ of filtrated solution in a separatory funnel. Three partitions with $10 \mathrm{~mL}$ of chloroform were performed. The collected organic extracts were separated in three portions, the solvent was evaporated and the containers were stored at $-20^{\circ} \mathrm{C}$ in order to perform the screening, the confirmation and the quantification of the mycotoxins.

The modified method of extraction and cleaning of the extract described by Tanaka et al. ${ }^{28}$ (procedure 2) consisted of weighing $10.00 \mathrm{~g}$ of sample with $100 \mathrm{~mL}$ of acetonitrile:water $(3: 1 \mathrm{v} / \mathrm{v})$. The extraction was carried out in an orbital shaking table at $200 \mathrm{rpm}$ at $25^{\circ} \mathrm{C}$ for $30 \mathrm{~min}$.
The liquid fraction was separated by filtration, the extract was defatted by liquid partition with $20 \mathrm{~mL}$ of hexane under slow shaking for $3 \mathrm{~min}$ and the acetonitrile:water phase was collected, this operation was performed twice. $4 \mathrm{~g}$ of sodium chloride were added to the defatted extract for the water removal. The acetonitrile was collected in a flat-bottomed flask evaporated at $70{ }^{\circ} \mathrm{C}$ in a rotary evaporator. The dry flask was washed with $30 \mathrm{~mL}$ of chloroform:methanol $(9: 1 \mathrm{v} / \mathrm{v})$, homogenized in ultrasonic bath for $1 \mathrm{~min}$, and then, the extract was transferred to a centrifuge tube. After the centrifugation, the organic phase (chloroform) was collected and dried under a nitrogen stream and the flasks were stored in a freezer.

The QuEChERS method (procedure 3) was developed by Anastassiades et al. ${ }^{29}$ and applied with some modifications. A sample of $10.00 \mathrm{~g}$ was weighed in a centrifuge flask and $20 \mathrm{~mL}$ of water were added. $20 \mathrm{~mL}$ of acidified acetonitrile with $0.2 \mathrm{~mL}$ of glacial acetic acid were added, followed by orbital shaking table at $200 \mathrm{rpm}$ at $25^{\circ} \mathrm{C}$ for $10 \mathrm{~min}$. Changes from the original methodology were due to the addition of salts and clean up. $1.5 \mathrm{~g}$ of magnesium sulfate was added, besides $0.85 \mathrm{~g}$ of sodium acetate, followed by orbital shaking table at $200 \mathrm{rpm}$ at $25^{\circ} \mathrm{C}$ for $10 \mathrm{~min}$. The material was centrifuged at a rotation speed of $3220 \times g$ for $8 \mathrm{~min}$ and $0.3 \mathrm{~g}$ of magnesium sulfate and $0.2 \mathrm{~g}$ of diatomaceous earth were added to the liquid phase, followed by manual shaking for $1 \mathrm{~min}$ and separation by centrifugation at $3220 \times g$ for $8 \mathrm{~min}$. The liquid phase was dried in a concentrator under a nitrogen stream.

The method was described by Liazid et al. ${ }^{36}$ (procedure 4) and applied with some modifications. It consisted in weighing of $5.00 \mathrm{~g}$ of sample in a centrifuge flask, for which $40 \mathrm{~mL}$ of acetonitrile:water (3:1 v/v) was added. The mixture was submitted to ultrasound for $30 \mathrm{~min}$ at $60 \mathrm{kHz}$. The extract was filtered after the addition of $2 \mathrm{~g}$ of sodium chloride to the defatted extract for water removal. The acetonitrile phase was collected in a separatory funnel and defatted with $10 \mathrm{~mL}$ of hexane extract by slow shaking. The operation was carried twice. The defatted extract was dried in a water bath at $50{ }^{\circ} \mathrm{C}$ under a nitrogen stream.

The dry residues that were obtained after the extractions were resuspended in benzene P.A. and shaken in ultrasound bath for $30 \mathrm{~s}$ before the chromatographic analysis.

Operational conditions in high performance liquid chromatography

The features of the liquid chromatograph were (Waters, Miliford, MA, USA) equipped with a photodiode array detector, PDA 2996, with quaternary pump model 
600, injector Rheodyne 7725i, loop injection of $20 \mu \mathrm{L}$, analytic column Synergi Fusion-RP $80 \AA$ A , Phenomenex ${ }^{\circledR}$ $(250 \times 4.60 \mathrm{~mm}, 4 \mu \mathrm{m})$ with data collecting system Empower PDA Software, isocratic elution system, with acetonitrile and purified water, acidified with phosphoric acid until $\mathrm{pH} 3.0$ $(50: 50 \mathrm{v} / \mathrm{v})$, flow of $1 \mathrm{~mL} \mathrm{~min}^{-1}$ with $20 \mathrm{~min}$ of run time.

Linearity covered the range from 1.5 to $7.5 \mu \mathrm{g} \mathrm{mL}^{-1}$ of each mycotoxin, in a total of six points and the record of the answering signal was outlined with the help of the data collecting system, which provided the coefficient of determination $\left(\mathrm{r}^{2}\right)$ and the equation of concentration versus signal, providing the limits of detection and quantification. ${ }^{37}$ Each concentration was injected three times and the values of the area averages were used to calculate the coefficients of variation for the accuracy analysis. The recovery was determined by the fortification of the sample in three different levels 3,4 and $6 \mu \mathrm{g} \mathrm{kg}^{-1}$ for citrinin and 8, 10 and $15 \mu \mathrm{g} \mathrm{kg}^{-1}$ for ochratoxin A.

\section{Results and Discussion}

The retention times in the best operation conditions were 10.8 and $13.4 \mathrm{~min}$ for CIT and OTA, respectively, and the total run time was $20 \mathrm{~min}$. Figure 3 shows the chromatogram of the two mycotoxins under study in a $254 \mathrm{~nm}$ wavelength, ideal to simultaneously detect the mycotoxins.

The readings of the maximum for the absorption spectrum were at $216 \mathrm{~nm}$ for ochratoxin A and $330 \mathrm{~nm}$ for citrinin. The spectral profiles were used to confirm the identity of both mycotoxins and to quantify them by the peak areas.

The LOD and LOQ values were 0.7 and $2.4 \mu \mathrm{gg}^{-1}$ for citrinin and 1 and $3 \mu \mathrm{g} \mathrm{kg}^{-1}$ for ochratoxin $\mathrm{A}$, respectively, and the analytical curves were linear in the range from 1.5 to $7.5 \mu \mathrm{g} \mathrm{mL} \mathrm{m}^{-1}$, being described by the equations $\mathrm{y}=8 \times 10^{3} \mathrm{x}+3.54 \times 10^{-3}$ for citrinin and $\mathrm{y}=4.9 \times 10^{3} \mathrm{x}+1.78 \times 10^{-3}$ for ochratoxin A. Tokusoglu and Bozoglu ${ }^{38}$ used the HPLC-FL (high performance liquid chromatography with fluorescence detection) to determine citrinin and ochratoxin $\mathrm{A}$ in olive samples, the obtained LOD value was $0.05 \mu \mathrm{gg}^{-1}$ for both CIT and OTA.

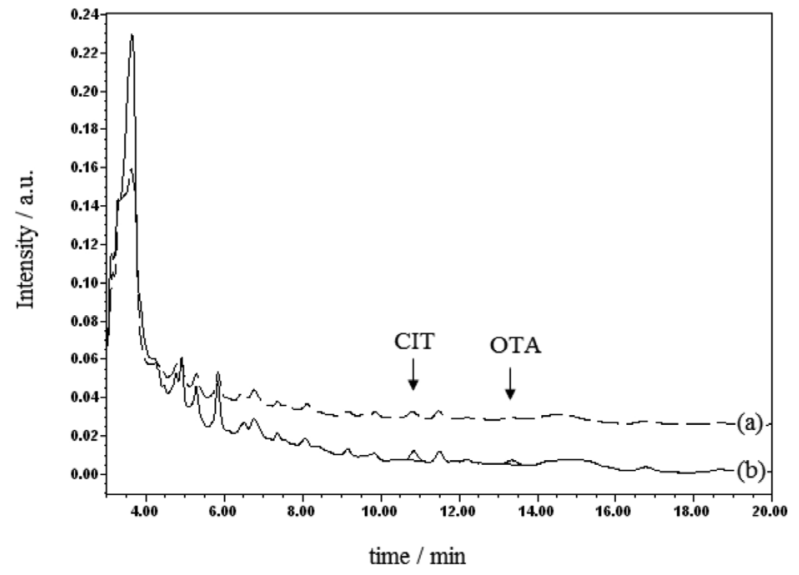

Figure 3. HPLC-PDA chromatograms in a $254 \mathrm{~nm}$ wavelength obtained from rice with the QuEChERS extraction procedure: (a) a rice non-fortified sample extract and (b) fortified with $3 \mu \mathrm{g} \mathrm{kg}^{-1}$ of CIT and OTA. Arrows indicates the retention times of the mycotoxins.

Ibáñez-Vea et $a l .{ }^{39}$ used the UHPLC-FL for determining aflatoxins $\left(\mathrm{B}_{1}, \mathrm{~B}_{2}, \mathrm{G}_{1}\right.$ and $\left.\mathrm{G}_{2}\right)$, ochratoxin $\mathrm{A}$ and zearalenone in breakfast cereal samples. The LOD and LOQ values were 0.062 and $0.2 \mu \mathrm{g} \mathrm{kg}^{-1}$ for ochratoxin, respectively. ${ }^{39}$

The determination coefficients $\left(\mathrm{r}^{2}\right)$ were 0.998 for both mycotoxins. The analytical curve for the relation between the concentration and the absorption of mycotoxin proved that the models are appropriate. This statement was achieved since a determination coefficient $\left(r^{2}\right)$ higher than 0.999 was considered an ideal adjustment of the data for the regression line ${ }^{37}$ After determining the best chromatographic conditions for the separation and the quantification of the mycotoxins under study, different aspects that were taken into consideration to compare the methods were evaluated, according to Table 1 . The most important data for the selection of the procedure were the sample mass, the number of phases and the amount of used solvents. Regarding these aspects, the QuEChERS method stood out.

According to Table 1, Soares ${ }^{27}$ and Tanaka ${ }^{28}$ extraction phases (in comparison with the ultrasound ${ }^{36}$ and QuEChERS $)^{29}$ show that a minimum number of phases and low consumption of solvents and materials turn QuEChERS into an attractive method. This is even if there is no difference in relation to the quantity of sample. Besides, because of

Table 1. Operational characteristics of the four extraction procedures under study

\begin{tabular}{lcccc}
\hline Procedure & Soares & Tanaka & QuEChERS & Ultrasound \\
\hline Sample mass / g & 50 & 10 & 10 & 5 \\
Extraction phase & $300 \mathrm{~mL} \mathrm{MeOH}: \mathrm{KCl}$ & $100 \mathrm{~mL} \mathrm{C}_{2} \mathrm{H}_{3} \mathrm{~N}: \mathrm{H}_{2} \mathrm{O}$ & $40 \mathrm{~mL} \mathrm{C}_{2} \mathrm{H}_{3} \mathrm{~N}: \mathrm{H}_{2} \mathrm{O}$ & $40 \mathrm{~mL} \mathrm{C} \mathrm{H}_{3} \mathrm{~N}: \mathrm{H}_{2} \mathrm{O}$ \\
Clean up - phase 1 & $150 \mathrm{~mL} \mathrm{H} \mathrm{H}_{2}$ distilled & $40 \mathrm{~mL} \mathrm{C}_{6} \mathrm{H}_{14}$ & $3 \mathrm{~g} \mathrm{MgSO}_{4} ;$ & $20 \mathrm{~mL} \mathrm{C}_{6} \mathrm{H}_{14}$ \\
& & & $1.7 \mathrm{~g} \mathrm{CH}_{3} \mathrm{COONa}_{2}$ & \\
Clean up - phase 2 & $30 \mathrm{~mL}\left(\mathrm{CHCl}_{3}\right)$ & $27 \mathrm{~mL}\left(\mathrm{MeOH}: \mathrm{CHCl}_{3}\right)$ & $\left.3 \mathrm{~g} \mathrm{Na}_{3} \mathrm{C}_{6} \mathrm{H}_{5} \mathrm{O}_{7} \mathrm{~N}\right)$ & $30 \mathrm{~mL}\left(\mathrm{C}_{2} \mathrm{H}_{3} \mathrm{~N}\right)$ \\
Residue / $\mathrm{mL}$ & 600 & 160 & 15 & 40 \\
\hline
\end{tabular}


the reduced volume in comparison with the other extraction systems, QuEChERS eliminates phases. The difference is in the extract cleaning which is carried out with salts and diatomaceous earth, thus, considerably decreasing the amount of solvents and the analyst exposure to them. Figure 3 shows the HPLC-PDA chromatogram obtained following the QuEChERS extraction procedure.

The recommended criteria for the evaluation by FAO (Food and Agriculture Organization) in Worldwide Regulation for Mycotoxins ${ }^{8}$ includes the percentage of recoveries for trace analysis $\left(\mu \mathrm{kg}^{-1}\right)$, such as the case of mycotoxin determination. The results of the interval of recoveries for each extraction procedure under study are presented in Table 2.

The modified QuEChERS method was used to evaluate the occurrence of ochratoxin $\mathrm{A}$ and citrinin in rice (Oryza sativa, L.) samples. Considering all 38 samples, ochratoxin A was found in the sample of rough rice which was stored in silos with $560 \mu \mathrm{g} \mathrm{kg}$-1 of contamination. This amount is higher than the recommended one by the Commission of the European Communities (the European Union regulatory agency), ${ }^{40}$ which establishes a maximum limit of $5 \mu \mathrm{g} \mathrm{kg}^{-1}$ and, by the Agência Nacional de Vigilância Sanitária (ANVISA, Brazilian regulatory agency) ${ }^{41}$ that recommends a maximum limit of $10 \mu \mathrm{g} \mathrm{kg}^{-1}$ for grains.

The citrinin occurred in one of the samples of parboiled rough rice with $120 \mu \mathrm{g} \mathrm{kg}^{-1}$ of contamination. Table 3 shows the quantified amounts by high performance liquid chromatography with a photodiode array detector (HPLC-FDA). The concentration that was determined for citrinin can also be considered high in comparison with the maximum limits established by the same legislation for mycotoxins that have similar effect to ochratoxin A.

The QuEChERS method was applied to the extraction of several analytes, such as mycotoxins. Sospedra et al. ${ }^{42}$ improved this methodology by using a mixture of

Table 2. Recoveries of ochratoxin and citrinin of the four extraction procedures studied by HPLC-PDA

\begin{tabular}{|c|c|c|c|c|}
\hline Procedure & Mycotoxins & Fortification level / $\left(\mu \mathrm{g} \mathrm{kg}^{-1}\right)$ & Recovery $^{\mathrm{a}} \%$ & $\mathrm{CV}^{\mathrm{a}} / \%$ \\
\hline \multirow{4}{*}{ Soares and Rodriguez-Amaya } & ochratoxin A & 8 & 71.6 & 2.8 \\
\hline & & 15 & 82.7 & 3.2 \\
\hline & citrinin & 3 & 55.5 & 1.8 \\
\hline & & 6 & 52.9 & 2.4 \\
\hline \multirow[t]{4}{*}{ Tanaka } & ochratoxin A & 8 & 89.0 & 2.2 \\
\hline & & 15 & 98.3 & 1.6 \\
\hline & citrinin & 3 & 64.0 & 3.4 \\
\hline & & 6 & 62.7 & 2.8 \\
\hline \multirow[t]{4}{*}{ QuEChERS } & ochratoxin A & 8 & 76.8 & 2.4 \\
\hline & & 15 & 105.3 & 4.8 \\
\hline & citrinin & 3 & 77.8 & 3.1 \\
\hline & & 6 & 75.9 & 1.8 \\
\hline \multirow[t]{4}{*}{ Ultrasound } & ochratoxin A & 8 & 54.7 & 2.5 \\
\hline & & 15 & 53.4 & 1.8 \\
\hline & citrinin & 3 & 48.3 & 3.3 \\
\hline & & 6 & 45.7 & 0.9 \\
\hline
\end{tabular}

CV: coefficient of variation; ${ }^{\mathrm{a}} \mathrm{n}=3$.

Table 3. Incidence and concentration of ochratoxin A and citrinin in rice samples analyzed by QuEChERS modified method

\begin{tabular}{|c|c|c|c|c|}
\hline \multirow[b]{2}{*}{ Samples } & \multirow[b]{2}{*}{ No. of analyzed samples } & \multirow[b]{2}{*}{ No. of positive samples } & \multicolumn{2}{|c|}{ Mycotoxins / $\left(\mu \mathrm{kg}^{-1}\right)$} \\
\hline & & & $\begin{array}{c}\text { OTA } \\
\text { LOD (1.0) }\end{array}$ & $\begin{array}{c}\text { CIT } \\
\text { LOD }(0.7)\end{array}$ \\
\hline Rough rice & 6 & nd & nd & nd \\
\hline Parboiled rough rice & 6 & 1 & nd & 120 \\
\hline Polished rice & 6 & nd & nd & nd \\
\hline White polished rice & 6 & nd & nd & nd \\
\hline Bran & 6 & nd & nd & nd \\
\hline Parboiled bran & 6 & nd & nd & nd \\
\hline Rough rice stored in silos & 1 & 1 & 560 & nd \\
\hline Bran stored in silos & 1 & nd & nd & nd \\
\hline
\end{tabular}

LOD: limit of detection; nd: non-detected. 
methanol:acetonitrile $(85: 15 \mathrm{v} / \mathrm{v})$ for the extraction of trichothecenes in wheat flour samples from Spain. High performance liquid chromatography with a mass detector (HPLC-MS) was used for determining these compounds, the recovery amounts ranged from 86 to $108 \%$, the values of the coefficients of variation were lower than $7 \%$ and the LOQ values varied from 4 to $100 \mu \mathrm{g} \mathrm{kg}^{-1}$. Zanella et $a l .^{32}$ performed a review of the QuEChERS method for the extraction of pesticide multiresidue in distinct food matrices. 52 pesticides were analyzed by gas chromatography with a mass detector (GC-MS) and 169 pesticides and 26 mycotoxins were analyzed by liquid chromatography with a mass detector (LC-MS). For simultaneous extraction, their recovery percentages ranged from 70 to $120 \%$ in the case of $100 \%$ of the pesticides and $80 \%$ of the mycotoxins. The LOQ values for the mycotoxins ranged from 1 to $100 \mu \mathrm{g} \mathrm{kg}^{-1} .{ }^{32}$

The QuEChERS method has shown efficient results when applied with mass spectrometry, but can also be applied with other detectors with satisfactory results. Hajslova et al..$^{43}$ used ultra-high performance liquid chromatography with a mass spectrometry utilizing an orbitrap (UHPLC/Orbitrap-MS) and time of flight (UPLC-TOF-MS) for the detection of mycotoxins of the group Fusarium, which were extracted from grain samples and products derived from grains. In order to extract them, the authors modified and adapted the QuEChERS method. The LOQ values ranged from 10 to $100 \mu \mathrm{g} \mathrm{kg}^{-1}$, the recoveries from 94 to $108 \%$ and the coefficients of variation were lower than $7 \%$ for UPLC-TOF-MS. The UHPLC/ Orbitrap-MS technique was used for raw extract analysis. ${ }^{43}$

The coexistence of multimycotoxins in grains is also mentioned by other authors. Pfohl-Leszkowiez et al. ${ }^{44}$ reported the occurrence of aflatoxin $\mathrm{B}_{1}$, ochratoxin $\mathrm{A}$ and citrinin in rice sold in five provinces in the center Vietnam. The co-occurrence of ochratoxin A, citrinin and fumonisin $\mathrm{B}_{1}$ was also reported by authors in grain samples sold in France. ${ }^{12}$ Villa and Markaki ${ }^{45}$ also used HPLC-FL in order to analyze the presence of aflatoxin $\mathrm{B}_{1}$ and ochratoxin $\mathrm{A}$ in 55 grain samples and, 19 out of 55 were contaminated with both mycotoxins.

In Brazil, many publications have reported the increase in the occurrence of mycotoxins in food and rations, ${ }^{46}$ resulting in a new legislation for mycotoxins in food and feed. The contamination with zearalenone (ZEN), ochratoxin A (OTA), citrinin (CIT) and trichothecenes is still low when compared to contaminations that are caused by aflatoxins (AFA $B_{1}, B_{2}, G_{1}$ and $G_{2}$ ). ${ }^{46}$ Sylos et al. ${ }^{11}$ used Soares and Rodriguez-Amaya method and, added a partition with cyclohexane to find evidence of the presence of ochratoxin A and aflatoxins in 68 rice samples (in São Paulo State, Brazil), but ochratoxin A was not found in any sample. Simas et $a l .{ }^{47}$ analyzed the occurrence of aflatoxins and ochratoxins in grains used for feeding dairy cattle (in Bahia State, Brazil). 80 samples were analyzed, but ochratoxins were not detected. However, the aflatoxins were detected in $33.75 \%$ of the samples with contamination levels ranging from 1 to $3 \mu \mathrm{g} \mathrm{kg}{ }^{-1}{ }^{47}$

Nunes et al. $^{48}$ detected OTA in rice samples (in Rio Grande do Sul State, Brazil), as well as the presence of Penicillium in non-positive samples due to the conditions of the analytical method. Dors et al. ${ }^{49}$ evaluated the occurrence of aflatoxin $B_{1}, B_{2}$, deoxynivalenol, ochratoxin $A$ and zearalenone in rice samples and only aflatoxin $B_{1}$ was found.

These data show the importance of developing an accessible and reliable methodology for mycotoxins evaluation in grain and foods. It should lead to smaller residue volumes for the constant monitoring of important grains in the world agribusiness. Therefore, it is possible to prevent damage to public health without causing much impact on the environment. It is important to mention that this procedure is also more economical. Thus, the determination of mycotoxins becomes more accessible for the control of grain contamination. Besides, food safety may be improved.

\section{Conclusion}

The results of this study show that the method of extraction and purification QuEChERS (modified) enables the simultaneous extraction of ochratoxin $\mathrm{A}$ and citrinin with reliable performance and a significant reduction in the volume of solvents (about 25 times). The importance of simple and accessible methodology was confirmed by the verification of contaminated samples by ochratoxin A and citrinin, even in a reduced number of samples, demonstrating the importance of assessing the presence of these mycotoxins.

\section{Acknowledgments}

The authors thank Conselho Nacional de Desenvolvimento Científico e Tecnológico (CNPq) for the sponsorships given to the Master's program and Instituto Riograndense do Arroz (IRGA) for providing the samples and for funding this study.

\section{References}

1. Richard, J. J.; Int. J. Food Microbiol. 2007, 119, 3.

2. Taniwaki, M.; Martins C.; Iamanaka B.; Leite R.; Vicente E.; Okazaki M.; REVNET-DTA 2004, 4, 1. 
3. Rupollo, G.; Gutkoski, L. C.; Martins, I. R.; Elias, M. C.; Ciênc. Agrotec. 2006, 30, 118.

4. Knasmuller, S.; Cavin, C.; Chakraborty, A.; Darroudi, F.; Majer, B. J.; Huber, W. W.; Ehrlich, B. A. Nutr. Cancer 2004, 50, 190.

5. Elmholt, S.; Rasmussenp, H.; Mycopathologia 2005, 150, 421.

6. World Health Organization (WHO); Some Naturally Occurring Substances: Food items and Constituents, Heterocyclic Aromatic Amines and Mycotoxins, vol. 56; International Agency for Research on Cancer (IARC): Lyon, France, 1993, p. 489.

7. Castegnaro, M.; Canadas, D.; Vrabcheva, T.; Petkova-Bocharova, T.; Chernozemsky, I. N.; Pfohl-Leszkowicz, A.; Mol. Nutr. Food Res. 2005, 50, 519.

8. Food and Agriculture Organization (FAO); Worldwide Regulations for Mycotoxins 1995. A Compendium, FAO Food and Nutrition Paper, No. 64, Rome.

9. Dilkin, P.; Biológico 2002, 64, 187.

10. Furlong, E. B.; Soares, L. A. S.; Vieria, A. P.; Dadalt, G.; Rev. Inst. Adolfo Lutz 1999, 58, 105.

11. Sylos, C. M.; Simionato, E. M. R. S.; Astray, R. M.; Rev. Inst. Adolfo Lutz 2003, 62, 123.

12. Molinié, A.; Faucet, M.; Castegnaro, M.; Pfohl-Leszkowicz, A.; Food Chem. 2005, 92, 391.

13. Costa, T. P.; Germano, P. M. L.; Germano, M. I. S.; Higiene Alimentar 2005, 19, 39.

14. Berndt, W. O. In Ochratoxin-Citrinin as Nephrotoxins; Llewellyn, G. C.; O’Rear; P. C., eds.; Plenum Press: New York, 1990, p. 55-56.

15. Chagas, G. M.; Oliveira, M. B. M; Campello, A. P.; Kluppel, M. L. W.; J. Appl. Toxicol. 1995, 15, 91.

16. Heber, D.; Lembertas, A.; Lu, Q. Y.; Bowerman, S.; Go, V. L. W.; J. Altern. Complement. Med. 2001, 7, 133.

17. Meister, U.; Eur. Food Res. Technol. 2004, 218, 394.

18. Bailly, J. D.; Querin, A.; Le Bars-bailly, S.; Benard, G.; Guerre, P.; J. Food Prot. 2002, 65, 1317.

19. Aziz, N. H.; Moussa, L. A. A.; Food Control 2002, 13, 281.

20. Madhyastha, M. S.; Marquardt, R. R.; Mais, A.; Borsa, J.; Frohlich, A. A.; J. Food Prot. 1994, 57, 48.

21. Treucksess, M. W. In Official Methods of Analysis of AOAC International; Horwitz, W., ed.; AOAC International: Gaithersburg, Md., 2003, p. 56B.

22. Monaci, L.; Palmisano, F.; Anal. Bioanal. Chem. 2004, 378, 1777.

23. González-Peñas, E.; Leache, C.; Bizcarte, M.; Obanos A. P.; J. Chromatogr., A 2004, 1025, 163.

24. Senyuva, H. Z.; Gilbert, J.; Ozcan, S.; Ulken, U.; J. Food Prot. 2005, 68, 1512.

25. Goldberg, D. M.; Soleas, G. S.; Yan, J.; J. Agric. Food Chem. 2001, 49, 2733.

26. Pfohl-Leszkowicz, A.; Molinié, A.; Castegnaro, M.; Revista Mexicana de Micologia 2004, 19, 7.

27. Soares, L. M. V.; Rodriguez-Amaya, D. B.; J. Assoc. Off. Anal. Chem. 1989, 72, 22.
28. Tanaka, T.; Yoneda, A.; Inoue, S.; Sugiura, Y.; Ueno, Y.; J. Chromatog., A. 2000, 882, 23.

29. Anastassiades, M.; Lehotay, S. J.; Stajnbaher, D.; Schenck, F. J.; J. AOAC Int. 2003, 86, 412.

30. Sulyok, M.; Berthiller, F.; Krska, R.; Schuhmacher, R.; Mass Spectrom. 2006, 20, 2649.

31. van Der Lee, M. K.; van Der Weg, G.; Traag, W. A.; Mol, H. G. J.; J. Chromatogr., A. 2008, 1186, 325.

32. Zanella, R.; Adaime, M. A.; Friggi, C. A.; Prestes, D. O.; Quim. Nova 2009, 32, 1620.

33. Schenck, F. J.; Hobbs J. E.; Bull. Environ. Contam. Toxicol. 2004, 73, 24.

34. Mol, H. G. J.; Plaza-Bolaños, P.; Zomer, P.; Rijk, T.; Stolker, A. A. M.; Mulder, P. P. J.; Anal. Chem. 2008, 80, 9450.

35. Spanjer, M.; Rensen, P.; Scholten, J. M.; Food Addit. Contam., Part A 2008, 25, 472.

36. Liazid, A.; Palma, M.; Brigui, J.; Barroso, C. G.; Talanta 2007, $71,976$.

37. Ribani, M.; Bottoli, C. B. G.; Collins, C. H.; Jardim, I. C. S. F.; Melo, L. F. C.; Quim. Nova 2004, 27, 771.

38. Tokusoglu, Ö.; Bozoglu, F.; Ital. J. Food Sci. 2010, 22, 284.

39. Ibáñez-Vea, M.; Martínez, R.; González-Peñas, E.; Lizarraga, E.; Cerain, A. L.; Food Control 2011, 22, 1949.

40. The Commission of the European Communities; Commission Regulation (EC) No. 472/2002 amending Regulation (EC) No. 466/2001, Official Journal of the European Communities, 2002, L75/18-20.

41. Agência Nacional de Vigilância Sanitária (ANVISA); Dispõe sobre Limites Máximos Tolerados (LMT) para Micotoxinas em Alimentos, Resolução RDC No. 7, Brasil, 2011.

42. Sospedra, I.; Blesa, J.; Soriano, J. M.; Mañes, J.; J. Chromatogr., A 2010, 1217, 1437.

43. Hajslova, J.; Zachariasova, M.; Lacina, O.; Malachova, A.; Kostelanska, M.; Poustka, J.; Anal. Chim. Acta 2010, 662, 51.

44. Pfohl-Leszkowicz, A.; Nguyen, M. T.; Tozlovanu, M.; Tran, T. L.; Food Chem. 2007, 105, 42.

45. Villa, P.; Markaki, P.; Food Control 2009, 20, 455.

46. Sabino, M.; Rodriguez-Amaya, D. B.; Braz. J. Microb. 2002, $33,1$.

47. Simas, M. S.; Botura, M. B.; Correa, B.; Sabino, M.; Mallmann, A. C.; Bitencourt, C. B. S. C.; Batatinha, J. M.; Food Control 2007, 18, 404.

48. Nunes, I. L.; Magagni, G.; Bertolin, T. E.; Badiale-Furlong, E.; Ciênc. Tecnol. Aliment. 2003, 23, 190.

49. Dors, G. C.; Pinto, L. A. A.; Badiale-Furlong, E.; LWT Food Sci. Technol. 2009, 42, 433.

Submitted: February 3, 2011

Published online: October 25, 2011 